Case report

\title{
Coronary sinus atresia in a pediatric case: Review of literature
}

\author{
Ozge Pamukcu ${ }^{\mathrm{a}, *}$, Nazmi Narin ${ }^{\mathrm{a}}$, Suleyman Sunkak ${ }^{\mathrm{a}}$, Aydin Tuncay ${ }^{\mathrm{b}}$, Ali Baykan ${ }^{\mathrm{a}}$, Kazim Uzum $^{\mathrm{a}}$ \\ ${ }^{a}$ Erciyes University Faculty of Medicine, Pediatric Cardiology Department \\ b Erciyes Universitesi, Tip Fakültesi, Çocuk Hastanesi 1, Kat Çocuk Kardiyoloji Bölümü, Melikgazi, Kayseri, Turkey
}

\section{A R T I C L E I N F O}

\section{Article history:}

Received 31 January 2016

Received in revised form 16 May 2016

Accepted 31 May 2016

Available online 7 June 2016

\section{Keywords:}

Coronary sinus

Atresia

Child

\begin{abstract}
A B S T R A C T
Introduction: Coronary sinus (CS) is the venous drainage system of the heart. Absence of the CS or CS ostium atresia is rarely seen cardiac malformations. Congenital absence of CS usually is found together with other cardiac malformations.

Case: A one day old newborn was referred to our hospital for cyanosis. His saturation was $84 \%$ patient was referred to cardiology unit. In echocardiographic examination hypoplastic left heart syndrome was revealed. Prostoglandin infusion was started, catheterization was planned for ductal stent implantation. Catheterization revealed the presence of persistent left superior vena cava (LSVC). When radiocontrast was given to LSVC, it drained to the CS. However CS did not drain to right atrium at normal anatomy. Coronary sinus drained to the base of right atrium, where right superior vena cava opened, via a tunnel shaped vein (shown by arrow and schematically in Fig. 1).

Discussion: Absence of coronary sinus is an extremely rare condition, and in patients with other congenital cardiac malformations. Such malformations can be managed surgically or percutaneously. But either method may disrupt coronary venous drainage therefore it should be paid great attention to the anatomy before doing these procedures. Also it is important to inform the cardiac surgeons before the operation of associated cardiac lesions. Conclusion: Coronary sinus atresia is a rare condition that should be kept in mind especially in complex heart defects; diagnosis is critical before starting surgical procedure.

(C) 2016 The Society of Cardiovascular Academy. Production and hosting by Elsevier B.V. All rights reserved. This is an open access article under the CC BY-NC-ND license (http://creativecommons.org/licenses/by-nc-nd/4.0/).
\end{abstract}

\section{Introduction}

Coronary sinus (CS) is the venous drainage system of the heart. Atresia of ostium or total absence of the coronary sinus is a rarely seen cardiac malformation. Congenital absence of CS usually is found together with other cardiac malformations; however, isolated congenital absence of CS is very rare. ${ }^{1}$

\section{Case}

A one day old newborn was referred to our hospital for cyanosis. He was born normal spontaneous vaginal way without any complication with good APGAR scores. His body weight was $3400 \mathrm{~g}$. Tachypnea and subcostal retractions were seen in his initial physical examination. Therefore he was taken to intensive care to follow up his respiration. His saturation was $84 \%$ and nasal oxygen therapy was started. His chest $\mathrm{x}$ ray was normal. After $4-5 \mathrm{~h}$ despite the oxygen therapy; there

\footnotetext{
* Corresponding author at: Erciyes University School of Medicine, Div. Pediatric Cardiology.

E-mail address: ozgepamukcu2002@yahoo.com (O. Pamukcu).

Peer review under responsibility of The Society of Cardiovascular Academy.
}

was no change in saturation level. So they asked us for echocardiography and the patient was referred to our hospital. Echocardiographic examination revealed hypoplastic left heart syndrome. Prostaglandin infusion was started; catheterization was planned for ductal stent implantation. Catheterization revealed presence of persistent left superior vena cava (PLSVC). When radio contrast was given to PLSVC, it drained to the CS. However CS did not drain to the right atrium at normal anatomy. Coronary sinus drained to the base of the right atrium, where right superior vena cava opened, via a tunnel shaped vein ( shown by arrow and schematically in Fig. 1).

\section{Discussion}

Great cardiac vein and Marshall vein unite to form coronary sinus which is located in the posterior atrioventricular groove that takes the venous drainage of the heart. ${ }^{2}$

Absence of coronary sinus is an extremely rare condition, and in patients with other congenital cardiac malformations, the differentiation of absence and atresia of CS may be difficult. ${ }^{3}$ It is usually diagnosed in autopsy series. Atresia of coronary sinus may associate some malformations like PLSVC, atrial septal defect, and abnormal pulmonary venous return. ${ }^{4,5,6}$ 


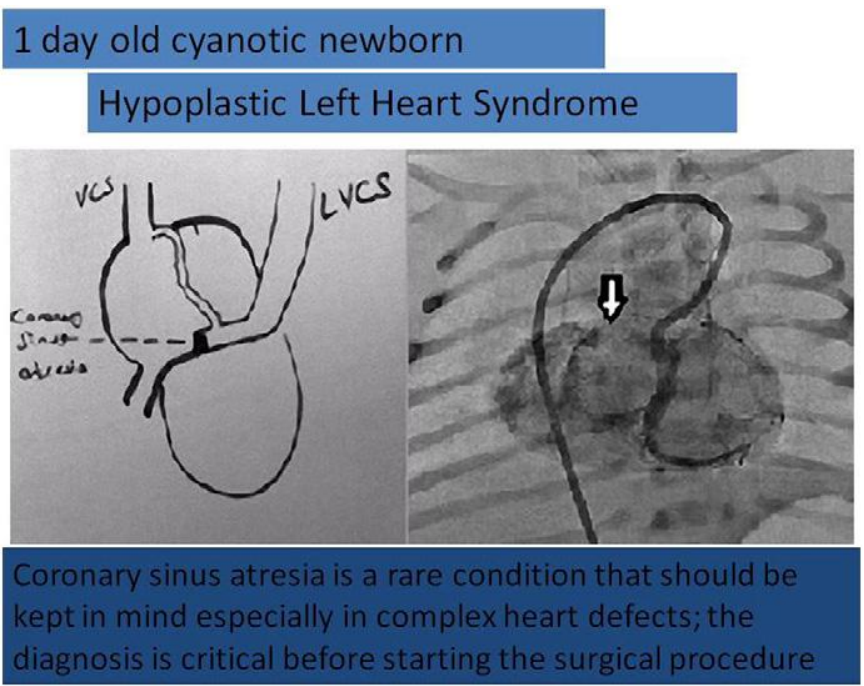

Fig. 1. Coronary sinus drained to the base of right atrium, where right superior vena cava opened, via a tunnel shaped vein (shown by arrow).

Thebesian veins were shown to drain directly into cardiac chambers or caval veins in patients with atresia of the CS ostium or congenital absence of the $\mathrm{CS}^{3}{ }^{3}$

Foale et al. reported a case of isolated congenital absence of the coronary sinus, with the left venous system draining into the left atrium via a narrowed great cardiac vein. The right venous system drained into the right atrium. ${ }^{1}$ Roa et al. reported a case of complete absence of the coronary sinus, with multiple small fistulae draining into the left ventricle ${ }^{7}$; both cases had no PLSVC.

Yolcu et al. presented two cases of isolated congenital absence of CS without any associated cardiac malformations. Both were 40 years old adults, coincidentally during coronary angiography it was found that their venous system draining directly into the left ventricle through Thebesian veins. ${ }^{8}$

Such malformations can be managed surgical or percutaneous. It was told that PLSVC and coronary fistulae may be occluded by coil embolization. Chen et al. reported a case of coronary atresia with a PLSVC and coronary fistulae. Coronary flow drained simultaneously into the left superior vena cava and right pulmonary artery via an abnormally large coronary fistula. Coronary anatomy was shown with CT imaging. A large fistula was occluded by coil. The patient was free of symptoms after transcatheter coil embolization. ${ }^{2}$
Ohta et al. described the surgical treatment of coronary orifice atresia in an infant with a persistent left superior vena cava after total cavo-pulmonary connection for hypoplastic left heart syndrome. After total cavo-pulmonary connection operation, cardiac performance deteriorated. Catheterization revealed coronary sinus atresia with a persistent left superior vena cava. The coronary sinus was fenestrated to the left atrium by reoperation. The patient survived surgical treatment of coronary sinus ostial atresia unroofed to the left atrium, guiding the placement of the fenestration with a probe placed through the open cardiac end of left superior vena cava. ${ }^{9}$

Coronary venous drainage may be disrupted either by the surgical binding or percutaneous closure. Therefore it should be paid great attention to the anatomy before doing these procedures. It is important to inform the cardiac surgeons before the operation of associated cardiac lesions. ${ }^{10}$ Because left SVC is usually ligated or occluded during cardiopulmonary bypass when there is a crossing vein between the left SVC and the right SVC. But it should be avoided if there is no coronary sinus orifice in the atrium.

\section{Conclusion}

Coronary sinus atresia is a rare condition that should be kept in mind especially in complex heart defects; the diagnosis is critical before starting the surgical procedure.

\section{References}

1. Foale RA, Baron DW, Rickards AF. Isolated congenital absence of coronary sinus. $\mathrm{Br}$ Heart J 1979;42:355-358

2. Chen CP, Lee KW, Liao CY, Huang CL. Coronary sinus atresia with cardiac veins draining into both the left superior vena cava and large coronary fistulae, treated by percutaneous coil embolization. Acta Cardiol Sin 2007;23:119-124.

3. Ogawa K, Hishitani T, Hoshino K. Absence of the coronary sinus with coronary venous drainage into the main pulmonary artery. Cardiol Young 2012:1-4 [Oct 19].

4. Bastarrika G, Simon-Yarza I, Gavira JJ. Incidental computed tomography diagnosis of a rare triad consisting of absence of coronary sinus, persistent left superior vena cava, and scimitar syndrome. Interact Cardiovasc Thorac Surg 2011;12:490-491.

5. Erol I, Cetin II, Alehan F, et al. Brain abscess associated with isolated left superior vena cava draining into the left atrium in the absence of coronary sinus and atrial septal defect. Cardiovasc Intervent Radiol 2006;29:454-456.

6. Vizzardi E, Fracassi F, Farina D, et al. Persistence of left superior vena cava, absence of coronary sinus and cerebral ictus. Int J Cardiol 2008;126:39-41.

7. Rao CV, Raghu K, Sharada K, Jaishankar S. Absent coronary venous sinus: a rare anomaly. Indian Heart J 2001;53:352-353.

8. Yolcu M, Turkmen S, Sertcelik A, Yolcu C, Batyraliev T. Isolated absence of coronary sinus: two cases report. J Clin Diagn Res 2013;7(12):3006-3007 [Dec].

9. Ohta N, Sakamoto K, Kado M, Nishioka M, Yokota M. Surgical treatment of coronary sinus orifice atresia with hypoplastic left heart syndrome after total cavo-pulmonary connection. Ann Thorac Surg 2002;73:653-655.

10. Janssen DR, Graham TP, Doyle TP, Moore JD. Occlusion of the coronary sinus ostium: a danger for cavopulmonary anastomosis. Catheter Cardiovasc Interv 2005;64:108-111. 